\title{
Biomedical Ethics and Regulatory Capacity Building Partnership for Portuguese-Speaking African Countries (BERC-Luso): A pioneering project
}

\author{
M Patrão Neves,' PhD; J P B Batista, ${ }^{2}$ PharmD \\ 1 University of the Azores, Faculty of Humanities and Social Sciences, Ponta Delgada, Portugal \\ ${ }^{2}$ Portuguese Pharmaceutical Society, Lisbon, Portugal
}

Corresponding author: J P B Batista (jorge.batista@ordemfarmaceuticos.pt)

\begin{abstract}
Biomedical research has a strong impact on a country's scientific-technological and socioeconomic development. It can make a significant contribution at three different levels: promotion of public health; the exchange of knowledge within the scientific community; and economic/ financial profitability. Africa only attracts $\sim 3.3 \%$ of the world's clinical research. This small proportion is due to, among several factors, the absence of two fundamental aspects: specific robust legislation and capacity for regulatory and ethical evaluation. There are five Portuguesespeaking African countries - Angola, Cabo Verde, Guinea-Bissau, Mozambique and São Tomé and Príncipe. Despite presenting different degrees of clinical research development, these countries show a common serious insufficiency in the minimum conditions necessary for hosting, collaborating or leading biomedical research projects. These countries are also excluded from the support of international organisations for capacity building because of the language barrier. The Biomedical Ethics and Regulatory Capacity Building Partnership for Portuguese-Speaking African Countries (BERC-Luso) project has developed methods to build capacity and partnership through research on national law, comparisons with international standards and by issuing recommendations at a national level. Through collaborative intensive training, trainees are taught to become educators at a national level. This, in turn, creates a sustainable impact at country level. BERC-Luso is a pioneering project, owing to a combination of innovative features. The partnership project: (i) was developed exclusively in Portuguese; (ii) involves a large number of African countries, and national and international institutions; (iii) has been further enhanced by the diversity and complementarity of its action plans; and (iv) has also benefited from a broad participatory methodology based on resolution of recipients' problems by the recipients themselves. It thus stands out as a model for similar future projects.
\end{abstract}

S Afr J Bioethics Law 2021;14(3):79-83. https://doi.org/10.7196/SAJBL.2021.v14i3.749

Biomedical research, especially including clinical trials, has been increasing, with the involvement of a growing number of multidisciplinary researchers and participants. ${ }^{[1]}$ Targeting a diversity of objectives and diseases, the volume of investment has increased through internationalisation. ${ }^{[2]}$ This new research environment is an important factor in the development of societies. ${ }^{[3]}$ For this reason, one of the main objectives of the European Clinical Trial Regulation of $2014^{[4]}$ was the creation of attractive conditions for conducting clinical trials in the European Union.

The wide range of benefits boosted by biomedical research can be structured into three fundamental and complementary categories:

- promotion and qualification of public healthcare, through access to state-of-the-art drugs and cutting-edge technologies, together with higher expertise and skills of healthcare professionals $s^{[2,3,5]}$

- widening and specialising of the scientific community, through its integration in international networks of knowledge and innovation, which are increasingly broad and multidisciplinary ${ }^{[3,5,6]}$

- boosting the economy and financial profitability, through both direct and indirect impacts on the real economic and financial activities of each country. ${ }^{[2,3,5]}$
Notwithstanding the strong positive direct and indirect impacts associated with biomedical research, it appears that its distribution worldwide is unbalanced, and particularly unfair to Africa. ${ }^{[7]}$ This is the poorest continent in the globe, composed of 54 countries with a population of 1340 billion inhabitants, and a gross domestic product (GDP) equivalent to USD2.34 trillion (2.72\% of world GDP), and the continent where biomedical research records the lowest value when compared with worldwide levels: only 3.3\% of biomedical research is done in Africa. ${ }^{[8-10]}$ This situation seems particularly perplexing given that Africa offers excellent and unique conditions for conducting clinical trials. Africa has a very diverse population, and one which has mostly not yet been exposed to any type of drug. This suggests an easy availability of clinical trial volunteers, within a treatment-naive patient population. ${ }^{[2,3]}$ The existence of a significant number of neglected endemic tropical diseases - such as dengue, chikungunya, human African trypanosomiasis and leprosy (Hansen's disease) - suggests an additional justification for conducting clinical trials that address unmet local needs. ${ }^{[11]}$

\section{Shortfall of biomedical research in Africa}

The current situation in Africa, as regards the shortfall of biomedical research and, particularly, of clinical trials, stems from 
a number of factors, among which we will highlight the leading two concerns.

\section{Historical reasons}

The first concerns relating to biomedical research in Africa are of a historical nature. They refer to the strong distrust from African countries in relation to biomedical research in general, and to clinical trials in particular. Unethical research has previously been conducted by foreigners on the continent, often within a general culture of abuse, particularly during the last quarter of the 20th century. Research was relocated from the so-called Western world to African countries, attracted by the lack of ethical legislation, and the possibility of double standard procedures. ${ }^{[12]}$ This resulted in the simplification and speeding up of research and, consequently, an increase in profits. At the same time, this new environment resulted in the abuse of vulnerable populations, who were used as a means to obtain the goals of scientific and pharmacological research companies. This led to a strong rejection of biomedical research in developing countries. Consequently, many African countries remain suspicious of and therefore uninterested in the implementation of biomedical research. ${ }^{[13]}$

\section{Legal reasons}

The second factor concerns the pharmaceutical industry, and is of a legal nature. It refers to the significant negative economic and financial impact inflicted on the pharmaceutical industry by media coverage of abusive research practices, particularly in Africa. ${ }^{[13]}$

We highlight, as an example, the Pfizer Trovan study in Nigeria, in which children were recruited as patients, some of whom died as a result of the effect of the drugs they received. Later it was discovered that the company had never obtained either authorisation from the relevant authorities, or ethical clearance to develop the clinical trial in the country, resulting in an illegal trial with an unregistered drug. This subsequently led to an international lawsuit, with massive damage to the company's image, a political scandal and a settlement of USD75 million in compensation. ${ }^{[14]}$

The absence of a proper legislative framework for the practice of biomedical research, and specifically to conduct clinical trials, facilitated - and was even viewed by the pharmaceutical industry as an opportunity for - the free implementation of its own projects, regardless of other interests. This unregulated activity opened up medical research to abuses that, once made known and disseminated by the media, led to international legal proceedings, with high costs, and to the detriment of the company's public image. These factors resulted in a growing lack of interest by those same companies in developing activities outside of a very robust legal framework that might prevent litigious action, and which might also guarantee stability and continuity to the ongoing research. Currently, research companies and, in particular, the pharmaceutical industry prefer to work within a robust ethical legal and regulatory framework, having withdrawn from and avoiding low- and middle-income countries, including many African nations, which do not offer the proper legal conditions for their activities. ${ }^{[15]}$

It is this briefly summarised situation that the project Biomedical Ethics and Regulatory Capacity Building Partnership for PortugueseSpeaking African Countries (BERC-Luso) intends to change, contributing to the creation of favourable conditions for the development of biomedical research in five Portuguese-speaking African countries. ${ }^{[16]}$

\section{The BERC-Luso project and its pioneering design, methodology and approach}

BERC-Luso was designed to improve ethical and regulatory capacity building within the scope of biomedical research aimed exclusively at Portuguese-speaking African countries. These countries are: Angola, with an area of 1246700 km$^{2}$ and 30809 million inhabitants; Cabo Verde, with an area of $4033 \mathrm{~km}^{2}$ and 543767 inhabitants; GuineaBissau, with an area of $36544 \mathrm{~km}^{2}$ and 1874 million inhabitants; Mozambique, with an area of $801590 \mathrm{~km}^{2}$ and 29496 million inhabitants; and São Tomé and Príncipe, with an area of $1001 \mathrm{~km}^{2}$ and 211028 inhabitants. ${ }^{[17-20]}$

It was known that biomedical scientific research in these countries is still incipient: there is no registry of clinical trials both in Cabo Verde and São Tomé and Príncipe, and only 3 clinical trials registered in Angola, 53 in Guinea-Bissau and 86 in Mozambique. ${ }^{[0]}$

In addition to the factors discouraging clinical research in Africa that have already been addressed, political instability has also had a strong negative impact on the quality of public administration, the smooth functioning of institutions, the employment stability of professionals, the integrity of social systems and the transparency of

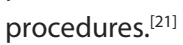

It was within this very specific context that BERC-Luso planned an intervention programme, acting within several domains and at multiple levels, some innovative in themselves but mostly pioneering in their convergence and synergetic power.

\section{Language}

Crucial to the first stage of structuring the project and facilitating the pursuit of its objectives was the language, namely Portuguese.

Portuguese is the fourth most commonly spoken language in the world, the fifth most used on the internet and the third on the social networks Facebook and Twitter; it is also the most widely spoken language in the southern hemisphere. ${ }^{[22]}$ It counts worldwide as having more than 265 million speakers and, despite co-existing with multiple other languages in African countries whose official language is Portuguese, is their internal lingua franca. ${ }^{[23]}$

In spite of this prevalence, the main international organisations that globally promote ethical and regulatory capacity building in biomedical research (such as the World Health Organization (WHO)), including national ethics committees (such as the United Nations Educational, Scientific and Cultural Organization (UNESCO)), have not made effective interventions in Portuguese-speaking African countries. This is specifically due to the language barrier. ${ }^{[2427]}$ The language revealed itself as an element of disadvantage and an exclusion factor that needs to be properly addressed.

BERC-Luso uses Portuguese in all of its intervention plans, thus reaching and involving a set of institutions and professionals previously though unintentionally - excluded from the acquisition of indispensable skills and practices for the implementation of clinical research at the highest levels.

\section{Partnerships}

The second stage of structuring the project and facilitating the pursuit of its objectives focused on the partnerships celebrated at both national and institutional levels. 


\section{National level}

At the national level, it was considered essential to bring together all five Portuguese-speaking African countries to create a Portuguesespeaking cluster that would mutually reinforce each partner country. This aspect is particularly important as three of the countries involved - Cabo Verde, São Tomé and Príncipe and Guinea-Bissau do not have an international profile, given their small size and island dispersion, leaving them at risk of remaining excluded from worldwide clinical research. Angola and Mozambique, two large countries and powerful players on the continent, are able to scale up to the three smaller ones, and are also themselves reinforced within this broad partnership.

\section{Institutional level}

At the institutional level and given the ethical and regulatory nature of the project, it was considered essential to bring together the national stakeholders responsible for ethical and regulatory revision, where they existed, and to contribute to their institutionalisation where they were absent. This encourages the sharing of common competencies that can be viewed from differing stakeholder perspectives, while also helping to establish new ones where they are required.

This approach has been implemented, whenever possible, in the five African countries, as well as within the Portuguese Consortium co-ordinating the project. This consortium brings together the National Authority of Medicines and Health Products, the National Ethics Committee for Clinical Research, the Portuguese Pharmaceutical Society and the Portuguese UNESCO Chair in Bioethics. ${ }^{[28-32]}$ The global partnerships have endeavoured to maintain adherence to regulatory aspects through the $\mathrm{WHO}$, and ethical considerations through UNESCO.

BERC-Luso was thus able to strengthen itself through the involvement of multiple institutions at national, African and European levels, as well as worldwide, a task assisted by the convergence of their common objectives.

\section{Action plans}

The design of BERC-Luso is essentially characterised by its general action plan, which adopts four lines of intervention that intersect as they unfold. ${ }^{[33]}$

\section{De legis}

The first, 'On legislation', focuses on the current legislation in the partner countries within the field of biomedical research and clinical trials, in a comparative analysis with international good practice, identifying the international requirements missing in national legislation. The objective is to contribute to the construction and consolidation of a legislative framework in line with international good clinical practice, so that Portuguese-speaking African countries can welcome, collaborate and lead international biomedical research projects.

\section{De educationis et de praxis}

The second and third action plans, 'On education' and 'On practice', respectively, focus on training different professionals for the regulatory and ethical evaluation of biomedical research projects, specifically those involving human participants in clinical trials. Professional training is the second requirement previously identified as essential to enable a country to undertake clinical research. It is expected that participants are able to act as educators to other professionals in each country, thus reinforcing long-term sustainability.

'On education' consists of a theoretical-practical educational programme in an intensive regime, from bioethical principles to its application in scientific research. 'On practice' addresses internships within Portuguese institutions that carry out the regulatory and ethical evaluation inherent to the entire scientific project. The goal is to establish and certify, in each partner country, a group of professionals who are familiar with the fundamentals and procedures of ethical-legal requirements for biomedical research within the framework of international good practice. Throughout the educationtraining programme, the respective national laws are reviewed, and appropriate changes are identified based on the needs of everyday practice.

\section{De rete}

'On connecting' refers to the fourth action plan, which starts at the launch of the project and will extend to its closure. The goal is to introduce new forms of online connection successively and cumulatively as the project unfolds: Facebook for comment sharing; a public website for registration and dissemination of all the actions of the project; and a private area of the website for the project's participants to work together, with open access to all the material gathered and produced throughout the project, creating a consultative and educational repository in Portuguese.

The innovative nature of BERC-Luso lies in combining different action plans, which work both in sequence and by their interaction, and which grant unity and coherence to a significantly broad and diversified project.

\section{Action strategies}

The pioneering design of BERC-Luso is strongly grounded in its methodology, that is, on the strategy implemented to achieve the proposed goals.

Broadly, the strategy implemented is developed in two opposite but simultaneous and complementary - directions: bottom up, from working professionals to political powers; and, in reverse, top down. Working professionals are the people who face daily concrete problems, identify real needs and have a pragmatic perception of the best solutions available. Political powers - particularly members of the government and specifically ministers of health - are the individuals who can decide and implement the necessary legal and administrative changes.

Three converging strategies were structured to pursue the project.

\section{Horizontal collaboration}

The participatory relationship between the parties is horizontal and not hierarchical. It is based on dialogue presenting the relevance of good clinical practice and on understanding the different (social, cultural, economic and political) contexts, on a joint effort to adapt international requirements to national realities (instead of a transposition) and peer collaboration.

Problems are identified by the African partners, as well as solutions. Partners benefit from the mediation of the project promoters who assist in the interpretation of problems and in the 
implementation of solutions. This is teamwork, and the partners' problems are solved by the partners themselves.

For example, the comparative legislative study between the national laws of partner countries and good international clinical practice was carried out by a team of lawyers from all partner

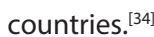

\section{Self-commitment}

The partnership of institutions and professionals in BERC-Luso is built on an assumption of varying commitments that flag the completion of each stage and foster those that follow. The partner institutions are committed by means of appointing their own professionals to be part of the project as trainees. Professionals are called in at different stages to draw up a declaration of commitment that consists of a realistic intervention plan of action, which is feasible in both the short and medium term, in the institution to which they belong and within their own sphere of influence. A declaration of commitment to African countries is also requested from international partner institutions, to explicitly state their support of the objectives being pursued. This formally explicit commitment holds everyone accountable.

\section{Political engagement}

BERC-Luso seeks to involve political power throughout its development, in order to enhance its interventions. The ministries of health of the various partner countries have signed up for membership of BERC-Luso. They are regularly informed about its development, and have each appointed a lawyer to join a legal team from all of the partner countries to review national legislation. The Angolan ministry of health has a cross-sectional project monitoring team assisting the national developments of BERC-Luso.

BERC-Luso has also involved ambassadors from all the partner countries accredited in Portugal, who are regularly informed about its developments, and who are directly involved in its public initiatives. For example, the relevant embassies have each designated an official representative to accompany a technical workshop and individual work carried out within the scope of the national legislative study. Meanwhile, the ambassadors of the partner countries participated in a round-table discussion at the first public event of the project. Ambassadors are also a privileged channel to the political and legislative power - the governments - of these geographically distant partner countries. ${ }^{[35]}$

The convergence of the three strategies has resulted in the strengthening of relationships and trust between the parties, in the intensification of the interventions and in the promotion of the objectives, in the effectiveness of the project and in the enhancement of its objectives.

\section{Conclusion}

The pioneering nature of BERC-Luso emanates from its design, methodology and approach, strongly marked by intercollaboration, self-commitment and political engagement of all partners, which in turn enhance its effectiveness. The goal is to build up the conditions required for this project to prevail beyond its term, by transforming each and every participant in this project into potential leaders of future projects, thus fostering a multiplying effect.
The BERC-Luso project has developed methods to build capacity and partnership through research on national law, comparisons with international standards and by issuing recommendations at a national level. Through collaborative intensive training, trainees are taught to become educators at a national level. This, in turn, creates a sustainable impact at country level.

This is a pioneering project owing to a combination of innovative features. The partnership project: (i) was developed exclusively in Portuguese; (ii) involves a large number of African countries, and national and international institutions; (iii) has been further enhanced by the diversity and complementarity of its action plans; and (iv) has also benefited from a broad participatory methodology based on resolution of recipients' problems by the recipients themselves.

BERC-Luso thus stands out as a model for similar future projects, particularly in countries with language barriers and similiar development levels.

Acknowledgements. The authors would like to acknowledge all BERCLuso partners.

Author contributions. MPN drafted the manuscript. JPBB provided substantial input and provided a critical revision of the manuscript. Both authors read and approved the final manuscript.

Funding. BERC-Luso is a project funded by the European and Developing Countries Clinical Trials Partnership under the grant agreement CSA2016ERC-1414, and by the Calouste Gulbenkian Foundation.

Conflicts of interest. None.

1. Gresham G, Meinert JL, Gresham AG, Meinert CL. Assessment of trends in the design, accrual, and completion of trials registered in ClinicalTrials.gov by sponsor type, 2000 - 2019. JAMA Netw Open 2020;3(8):e2014682. https://doi.org/10.1001/ jamanetworkopen.2020.14682

2. Lang T, Siribaddana S. Clinical trials have gone global: Is this a good thing? PLoS Med 2012;9(6):e1001228. https://doi.org/10.1371/journal.pmed.1001228

3. Weigmann K. The ethics of global clinical trials: In developing countries, participation in clinical trials is sometimes the only way to access medical treatment. What should be done to avoid exploitation of disadvantaged populations? EMBO Rep 2015;16(5):566-570. https://doi.org/10.15252\%2Fembr.201540398

4. European Union. Regulation (EU) Nr 536/2014 of the European Parliament and of the Council of 16 April 2014 on clinical trials on medicinal products for human use, and repealing Directive 2001/20/EC. https://ec.europa.eu/health/ sites/default/files/files/eudralex/vol-1/reg_2014_536/reg_2014_536_en.pdf (accessed 21 June 2021).

5. Schulz-Baldes A, Vayena E, Biller-Andorno N. Sharing benefits in international health research: Research-capacity building as an example of an indirect collective benefit. EMBO Rep 2007;8(1):8-13. https://doi.org/10.1038\%2Fsj.embor.7400886

6. Glickman SW, McHutchison JG, Peterson ED, et al. Ethical and scientific implications of the globalisation of clinical research. N Engl J Med 2009;360(8):816-823. https:// doi.org/10.1056/nejmsb0803929

7. Miiro GM, Ouwe Missi Oukem-Boyer O, Sarr O, et al. EDCTP regional networks of excellence: Initial merits for planned clinical trials in Africa. BMC Public Health 2013;13(1):258. https://doi.org/10.1186/1471-2458-13-258

8. United Nations. World population prospects - population division. https:// population.un.org/wpp/DataQuery/ (accessed 5 April 2020).

9. World Bank. GDP (current US\$) - Sub-Saharan Africa, Algeria, Djibouti, Egypt, Arab Rep., Libya, Morocco, Tunisia. https://data.worldbank.org/indicator/NY.GDP. MKTP.CD? end=2018\&locations=ZG-DZ-DJ-EG-LY-MA-TN\&start=2018\&view=bar (accessed 5 April 2020).

10. US National Library of Medicine. ClinicalTrials.gov. www.clinicaltrials.gov (accessed 5 April 2020).

11. Rebollo MP, Bockarie MJ. The challenges of conducting clinical trials for neglected tropical diseases. Clin Investigation 2015;5(6):535-537. https://www. openaccessjournals.com/articles/the-challenges-of-conducting-clinical-trials-forneglected-tropical-diseases.pdf (accessed 24 June 2021). 
12. Salhia B, Olaiya V. Historical perspectives on ethical and regulatory aspects of human participants research: Implications for oncology clinical trials in Africa. JCO Glob Oncol 2020;(6):959-965. https://doi.org/10.1200\%2FJGO.19.00196

13. Weyzig F, Schipper I. SOMO briefing paper on ethics in clinical trials \#1: Examples of unethical trials. Amsterdam: SOMO - Centre for Research on Multinational Corporations, 2008. https://www.somo.nl/wp-content/uploads/2008/02/ Examples-of-unethical-trials.pdf (accessed 5 April 2020).

14. Okonta PI. Ethics of clinical trials in Nigeria. Niger Med J 2014;55(3):188-194. https:// doi.org/10.4103\%2F0300-1652.132035

15. Maïga $\mathrm{D}$, Akanmori BD, Chocarro L. Regulatory oversight of clinical trials in Africa: Progress over the past 5 years. Vaccine 2009;27(52):7249-7252. https://doi. org/10.1016/j.vaccine.2009.08.113

16. BERC-Luso - Biomedical ethics and regulatory capacity building partnership for Portuguese-speaking African countries.https://www.berc-luso.com/EN (accessed 8 February 2021).

17. Republic of Angola. Official website of the government of the Republic of Angola. http://www.governo.gov.ao/Default.aspx (accessed 5 April 2020).

18. Cabo Verde. Official website of the government of Cabo Verde. https://www. governo.cv/ (accessed 5 April 2020)

19. Mozambique. Official website of the government of Mozambique. https://www. portaldogoverno.gov.mz/ (accessed 5 April 2020)

20. World Bank Group. International development, poverty, and sustainability. https:// data.worldbank.org/indicator/SP.POP.TOTL (accessed 5 April 2020).

21. Galjour J, Havik P, Aaby P, Rodrigues A, Mpinga EK. Chronic political instability and the HIV/AIDS response in Guinea-Bissau from 2000 to 2015: A systematic review. Trop Med 2021;6(1):36. https://doi.org/10.3390/tropicalmed6010036

22. Camões Institute for Cooperation and Language, Ministry of Foreign Affairs. https:// www.instituto-camoes.pt/images/eplp/Diptico dlp16.pdf (accessed 17 April 2020).

23. United Nations Educational, Scientific and Cultural Organization. Proclamation of a World Portuguese Language Day. UNESCO Digital Library. https://en.unesco.org/ commemorations/portuguese-language-day (accessed 17 April 2020).

24. United Nations Educational, Scientific and Cultural Organization. UNESCO, and specifically the Division of Ethics of Science and Technology, supports Ethics Committee mostly through its Assisting Bioethics Committees (ABC) programme. UNESCO, 2020. https://en.unesco.org/themes/ethics-science-and-technology/ assisting-bioethics-committees (accessed 20 May 2020).
25. World Health Organization. Capacity building and initiatives. https://www. who.int/teams/health-promotion/tobacco-control/implementing/capacitybuilding (accessed 29 November 2021).

26. World Health Organization. Capacity building. https://www.who.int/violence injury_prevention/capacitybuilding/en/ (accessed 21 June 2021).

27. World Health Organization. About the ePORTUGUÊSe network. https://www. who.int/eportuguese/mission/en (accessed 20 May 2020).

28. Portuguese Consortium of BERC-Luso. Biomedical ethics and regulatory capacity building partnership for Portuguese-speaking African countries. https://www.berc-luso.com/EN/?targetPage=insituicoes\&Area=78 (accessed 20 May 2020).

29. INFARMED - National Authority of Medicines and Health Products, I.P. https:// www.infarmed.pt/web/infarmed-en/ (accessed 20 May 2020).

30. CEIC - National Ethics Committee for Clinical Research. https://www.ceic.pt/ pagina-inicial (accessed 20 May 2020).

31. Ordem dos Farmacêuticos. Portuguese Pharmaceutical Society. https://www. ordemfarmaceuticos.pt/pt/ (accessed 20 May 2020).

32. Universidade Católica Portuguesa, Católica Porto Portuguese, UNESCO Chair in Bioethics (Institute of Bioethics, Portuguese Catholic University). https://www. bioetica.porto.ucp.pt/ (accessed 20 May 2020).

33. BERC-Luso. BERC-Luso work packages. BERC-Luso, 2019. https://www.berc-luso. $\mathrm{com} / \mathrm{EN} /$ ?targetPage=programasdeaccao\&Area=76 (accessed 20 May 2020).

34. Martinho da Silva P. BERC-Luso - estudo legislativo comparativo: Práticas internacionais e desafios legislativos. BERC-Luso, 2019. https://www.bercluso.com/projectobercluso/files/Estudo\%20legislativo\%20comparativo-\%20 pr\%C3\%A1 ticas\%20internacionais\%20e\%20desafios\%20legislativos.pdf (accessed 20 May 2020)

35. Symposium BERC-Luso. Biomedical ethics and regulatory capacity building partnership for Portuguese-speaking African countries. Lisbon: BERC-Luso, 2019. https://www.berc-luso.com/simposio/\#programa (accessed 30 June 2021).

Accepted 28 September 2021. 